\title{
China's Population Aging, Human Capital and Economic Growth -Comparison with the United States, Japan, and Korea
}

\author{
Mingliang Zhu ${ }^{1}$, Tiegang Zhang ${ }^{2}$
}

\author{
${ }^{1}$ Ph.D., School of Economics, Central University of Finance and Economics, Beijing, China. \\ Email: zhumingliangcufe@163.com \\ ${ }^{2}$ Professor, School of Economics, Central University of Finance and Economics, Beijing, China.
}

\begin{abstract}
This paper focuses on the status quo of China's population aging, that is, the current Chinese society is faced with the characteristics of aging: (1) the age structure of the labor force is aging, and there is a tendency to catch up with Japan and South Korea ; (2) the old-age dependency ratio and the child-rearing ratio rise simultaneously that brings double pressure to society ; (3) China's process of enrichment in the old process is also accelerating ; (4) The rapid rise of aging is slowly coming. At the same time, the related researches on the aging of the population in this field are discussed, and the relationship between population aging and human capital is complicated. The aging of the population affects the human capital transmission on economic growth, positive for economic growth or negative. At the same time, this paper compares the status quo of China's population aging with the three typical aging countries: the United States, Japan, and Korea.
\end{abstract}

Keywords-population aging, human capital, economic growth.

\section{CHINA'S POPULATION AGING}

"Old before getting rich", "the number of older people is the most", "aging fast" have been features of Chinese population aging and there are sufficient data validation and support. However, these research conclusions have been going on for more than ten years. During this period, China's industrial structure has undergone major changes, and the social economy has also made great achievements. It is accompanied by the aging of the population.

China is experiencing a continued increase speed of population aging process. In 2015, population over 60 years old reached 220 million, $16.1 \%$ of the total population, population over 65 years old reached 144 million, $10.5 \%$ of the total population. And according to the UN's forecast, In the next 40 years, the population over 60 years old will exceed 500 million. In the 1970s, Chinese fertility rate began to decline, while the population aging gradually began. In the thirty years of the implementation of family planning policy, the gender imbalance and the labor force reduction have become an increasingly serious problem, prompting the Chinese family planning policy adjustments. Finally in October 2015, the eighteenth Central Committee of the Communist Party of China the fifth plenary meeting communique pointed out that two children "to promote the balanced development of population, adhere to the basic state policy of family planning, improve the population development strategy, the full implementation of a couple's policy of giving birth to two children to actively carry out as the response to population aging". From the demographic factors, fertility and mortality are two basic factors that affect population aging, but the change of fertility rat is more elusive, and the affect of family planning policy is difficult to predict, after all the willingness to give birth, the economic level of the country, and the security system will directly affect the fertility level.

Population aging has been a global trend, while Chinese population policy is more unique. China's population aging has the following characteristics.

(1) The age structure of the labor force is aging, and there is a tendency to catch up with Japan and South Korea.

Aging is not only a process of increasing the proportion of the elderly population, but also a process of gradual aging of the working-age population. The latter has a farreaching impact on economic development. In 2015, Chinese older labor force is $37.68 \%$ of the total workforce, the ratio will continue to rise to $47.45 \%$ in 2040 , followed by the 10 years the ratio will be basically stable at $47 \%$. The elderly labor force accounts for almost half of the entire workforce. Labor is one of the core elements of economic growth, and the aging of labor will 
inevitably have a major impact on the socio-economic development of a country or region.

(2)The dual pressures of rising old-age dependency ratio and Child rearing ratio.

The old-age dependency ratio refers to the ratio of the population of the elderly aged 65 and over to the labor force of 15-64 years old, in order to measure the burden of the labor force supporting the elderly population. In 2015, the old-age dependency ratio in China was $13 \%$. According to UN's predictions, over the next 45 years China's old-age dependency ratio will rise rapidly, will be as high as $61.1 \%$. The growth rate is second only to South Korea(55 percent). In the meantime, Chinese total social dependency ratio will be improved significantly. The next 10 years, Chinese child dependency ratio would have been higher than the old-age dependency ratio, but by 2030, old-age dependency ratio will exceed the child dependency ratio by $3.5 \%$, older people will become the main social support burden in China.

(3)China's process of enrichment in the old process is also accelerating.

If China's aging population is "not getting rich first", China's economic level has further improved in recent years. At present, China's economic aggregate has ranked second, second only to the United States, and whether the aging level is still ahead of The level of economic development? In the 1980s, domestic scholars compared China's population aging and economic development level, and proposed that the characteristics of population aging are "not getting rich first". As of 2015, the proportion of elderly people aged 65 and over in China increased from $7 \%$ in 2000 to $10.5 \%$. In that year, the per capita GNI in China was $\$ 7,880$, while the per capita GNI in the United States, Japan, and South Korea reached this ageing level. For $\$ 8070, \$ 10,950$ and $\$ 21,530$, it is 1.02 times, 1.39 times and 2.73 times that of China. When the degree of aging in these four countries is $7 \%$, the per capita GNI of the United States, Japan, and South Korea is 1.66 times, 2.31 times, and 10.12 times that of China, respectively. Compared with 2000, the gap between China's per capita GNI and other three countries in 2015 has been significantly reduced. This shows that although China's aging is deepening in the past 15 years, the economy has developed more rapidly.

From the perspective of urbanization level, the proportion of urban population in China in 2015 was $56.1 \%$, while in the United States, Japan and South Korea, when the aging level reached $10.5 \%$, the proportion of urban population had reached $73.5 \%, 76.7 \%$ and $81.5 \%$ respectively. They are $17.4 \%, 20.6 \%$ and $25.4 \%$ higher than China respectively. This shows that under the same level of aging, China's urbanization level is still far lower than these three countries. However, compared with 2000, the gap in the level of urbanization between China and the other three countries is greatly narrowing. When the aging level of the four countries is $7 \%$, the highest level of urbanization in Korea is $44.28 \%$ higher than that in China. When the aging level of the four countries is 10.5 , the highest level of urbanization in Korea is $25.4 \%$ higher than that in China, and the gap is reduced by 18.88 . \%. In addition to the level of urbanization, China's industrialization and modernization levels have greatly improved over the past 15 years. Compared with the situation of the four countries when the degree of aging is $10.5 \%$, the proportion of the tertiary industry in Japan and South Korea is $2.2 \%$ and $9.8 \%$ higher than that of China respectively. When the aging of the three countries is $7 \%$, the proportion of the tertiary industry in Japan is higher. China's $10.4 \%$, South Korea is $18.1 \%$ higher than China's, showing that under the same ageing, the gap between China and these countries in the proportion of the tertiary industry is also narrowing.

\begin{tabular}{|c|c|c|c|c|c|}
\hline Ageing & years & $\begin{array}{c}\text { countr } \\
\mathrm{y}\end{array}$ & $\begin{array}{c}\text { Per } \\
\text { capita G } \\
\text { NI } \\
\text { (US\$) }\end{array}$ & $\begin{array}{c}\text { Urban } \\
\text { populati } \\
\text { on share } \\
(\%)\end{array}$ & $\begin{array}{c}\text { The } \\
\text { proportio } \\
\mathrm{n} \text { of the } \\
\text { tertiary } \\
\text { industry } \\
(\%)\end{array}$ \\
\hline \multirow{4}{*}{$\begin{array}{c}\text { Older } \\
\text { than } 7 \%\end{array}$} & 2000 & China & 840 & 36.92 & 33.4 \\
\hline & 1999 & Korea & 8490 & 81.2 & 51.5 \\
\hline & 1970 & Japan & 1940 & 72.1 & 43.8 \\
\hline & 1944 & $\begin{array}{l}\text { United } \\
\text { States }\end{array}$ & 1392 & 64 & - \\
\hline \multirow{4}{*}{$\begin{array}{c}\text { Older } \\
\text { than } 10 . \\
5 \%\end{array}$} & 2015 & China & 7880 & 56.1 & 50.5 \\
\hline & 2008 & Korea & 21530 & 81.5 & 60.3 \\
\hline & 1985 & Japan & 10950 & 76.7 & 52.7 \\
\hline & 1975 & $\begin{array}{l}\text { United } \\
\text { States }\end{array}$ & 8070 & 73.5 & 60.4 \\
\hline
\end{tabular}

Source: Yearbook -1995 / $2010 "$.

From a series of socio-economic indicators, it can be found that the gap between China and the developed countries is shrinking. However, under the same aging level, China's economic development is still far behind the United States, Japan, and South Korea. Rich while aging has become a prominent feature of China's current population aging, and the matching between old and rich is increasing significantly.

(4) The rapid rise in aging is coming quietly.

In the first half of this century, the proportion of elderly people aged 80 and over in China is not high, but China's aging population has its own outstanding characteristics: 
First, the population of aging population is huge; second, the population of aging population is growing fast, according to the UN. It is predicted that the growth rate of the proportion of the elderly population in China after ten years will be second only to the developed countries such as the United States, Japan and South Korea. Under the huge impact of the upcoming aging, China should seize the slower growth period of aging in the next decade.

Aging is an inevitable trend of population aging, which is affected by both the population cohort and the prolonged life expectancy of the population. China's life expectancy has increased from 43.39 in the early days of the founding of the People's Republic of China to 75.43 years in 2015 . Older people have a higher risk of disability, and the demand for nursing care is higher. At present, there are about 40.63 million disabled and semi-disabled elderly people in China, and the disability rate of the elderly is much higher than that of the younger. According to different disability standards, the disability rate of Chinese senior citizens is between $6.6 \%$ and $41 \%$. In fact, even elderly people with mild or partial disability need a certain degree of care. Therefore, under the premise that there is no fundamental change in the disease and health model, the increase in the number of elderly people means an increase in the number of elderly people with disability. According to the high old age disability rate of $30 \%$, China's current elderly disabled are estimated at 6.7 million. According to the United Nations, the number of elderly disabled people in China will reach 9.45 million, 17.99 million and 36.71 million respectively in 2025 , 2035 and 2050.

Compared with the United States, Japan and South Korea, China's aging has its own unique characteristics and policy adjustments. Aging has a profound impact on different countries, while China, the United States, Japan and South Korea have adopted different measures to reduc the negative effects. The ultimate goal of this paper is to explore the impact of population aging on the Chinese economy, but introduces a mediator of human capital. Through the impact of population aging on human capital to explore its final impact on the economy, and horizontally compare the impact of population ageing in different countries in China, Japan, and Korea on the domestic economy. In response to the US, Japan and Korea's policy of responding to the aging of the population, we will provide suggestions for China's aging population in the future, and a more stable transition to the aging population facing the United States, Japan and South Korea.

\section{THE IMPACT OF AGING ON HUMAN}

\section{CAPITAL}

Stiglitz emphasized the importance of human capital in the report of the International Committee on Economic Performance and Social Progress. He pointed out that human capital is an indicator of "surpassing gross domestic product" to measure economic development and social progress, and "human capital is an individual with the knowledge, skills, abilities and qualities that can create personal, social and economic well-being, it is not difficult to see that the aging of the population will inevitably bring about changes in knowledge, skills, abilities and qualities. It is certain that the aging of the population will inevitably change human capital. Since the reform and opening up, China's economy has grown rapidly. Studies have shown that human capital plays an important role in improving China's economic efficiency and narrowing regional differences (Fleisher, Li and Zhao, 2009). Human capital is considered to be a major contributor to the "Chinese economic miracle" (Fleisher and Chen, 1997; Démurger, 2001).

The aging of the population and the decline in the birth rate have brought about the lack of labor supply, which is not conducive to the sustained growth of the economy. The impact of human capital brought about by this aging phenomenon has become a hot issue for scholars. Since most countries with developed global economic levels are facing an aging population, scholars from all countries have explored the impact of human capital on the aging of the population. Because of the different backgrounds of research, it is unfavorable and beneficial. Many ideas of mixed theory exist.

According to the "favorable theory" scholars believe that mature labor work experience will continue to accumulate, and the decline in fertility rate gives young people the opportunity to receive higher education, so human capital is accumulated (Liu Yufei, 2016; Yao Congrong, 2008). Choi (2015) introduced human capital and physical capital accumulation in the OLG model, which proves that aging has obvious long-term effects on the economy, and aging will give more investment to the next generation of human capital; and he takes the Korean population as an example. It was found that the aging population in South Korea reduced the growth of labor supply, but it brought about an increase in wages, which in turn promoted human capital investment. Zhong Shuiying (2016) considers the advantages and disadvantages of population aging from the perspective of "dividends". He believes that "educational dividends" have a substitution effect on "demographic dividends", and the improvement of education level can alleviate or 
even offset the negative effects of the disappearance of demographic dividends.

The "unfavorable" view is that human capital investment will decline with age. Becker (1966) believes that when human capital is gradually accumulating, the increase in age will lead to a decrease in the marginal return of investment. From the perspective of opportunity cost, aging will lead to a decrease in human capital investment. From the perspective of the group, the rise in the proportion of the elderly population will inevitably lead to heavier political pressure, which will inevitably lead to an increase in social welfare and medical expenditures. Social expenditures are more inclined to the elderly population, which occupies other aspects of public expenditure. Miller (1996) studied the education expenditures of 48 continents and Texas counties to study the impact of the proportion of people over 65 years old on adult per capita education expenditure. The results show that aging will reduce education expenditure. Poterba (1997) believes that the aging of the population leads to an increase in life expectancy, which means that the post-retirement time is longer. In order to protect the elderly consumption, the elderly will reduce the human capital investment for their children. Some scholars directly believe that the aging of the population will lead to the deterioration of the quality of human capital, because the elderly are outdated and their ability to innovate declines. Even though the quality of human capital in the elderly population is improving, it is still lower than that of young people, so the ageing of humans has a negative impact on human capital (Cepar, 2015).

Scholars with a "mixed theory" view believe that the relationship between aging and human capital is complex and non-monotonic. Zhang (2003) found that the decline in adult mortality and the "hump-type" relationship between public education expenditures through the construction of the OLG model, when the life expectancy is relatively low, the median age voters tend to increase the tax rate to increase public human capital. Investment, when the aging reaches a certain level, the median age people turn to support the reduction of tax rate to reduce public human capital investment, and ultimately the speed of human capital accumulation is first rising and then falling.

Summarizing the above three viewpoints, we find that most scholars discuss the impact of aging on government human capital investment from a macro perspective, and more from the perspective of intergenerational conflicts from the perspective of social relations. In particular, foreign scholars are less likely to study from a microscopic perspective. In fact, there is a certain social background. Because Western developed countries have entered an aging age earlier, a relatively complete social security and education system has been established. Elderly care and education for minors are Social pooling (Chetty, 2012), so micro-family decision-making has less impact. At the same time, because the system does not emphasize the support of the children to the parents (Fei Xiaotong, 1983; Li Jinbo, 2011), the pension burden will not have a micro impact on human capital investment. China is not the same as the developed countries in the West. China has entered an aging society before it is rich (Cai Wei, 2016). The social security mechanism is currently unable to meet the needs of the elderly. The family not only undertakes pensions but also undertakes family education. Therefore, we must weigh the balance between pension and education. The family generations in China present feedback characteristics, and the pension burden will be fed back to the family human capital investment.

No matter from what angles, the existing research results show that the aging of the population will have an impact on human capital, and the impact is increasingly farreaching. It has become the focus of more and more scholars at home and abroad. However, due to different social backgrounds, resource endowments, and research perspectives, there is no final conclusion about the exact relationship between population aging and human capital. It is precisely because of the uncertainty of this relationship that the impact of population aging economic growth presents a more complex relationship.

\section{THE IMPACT OF HUMAN CAPITAL ON ECONOMIC GROWTH}

Most of the existing research on human capital and socioeconomics focuses on the roles of health and education. Health as an important part of human capital (Grossman, 1972), its status and changes have an increasing impact on national economic growth. Foreign scholars have also shown through data that health has a significant role in promoting economic growth, and that a significant portion of the contribution of long-term economic growth can be explained by health (Mayer, 2001; Arora, 2001). Whether China's economic growth has the same relationship with healthy capital, some scholars examine the relationship between health and wage income through a microscopic perspective to prove the positive relationship between healthy capital and economic growth (Zhang Chewei, 2003; Wei Zhong, 2004). Some scholars in China have directly verified from the empirical point of view that there is a significant positive correlation between healthy human capital and economic growth, and 
the elasticity of health index to economic growth is about 0.08, which suggests that China should strengthen the emphasis on health care. (Luo Kai, 2006). Some scholars have studied in theory, considering the effects of food consumption and nutrition on healthy human capital in the extended Ramsey model, thus exploring the relationship between healthy human capital, physical capital and consumption, and studying health versus longterm economy. The results of the study indicate that Fogel-type healthy human capital can expand economic growth in the presence of exogenous technological advances (Wang Dihai, 2012).

Over the years, the level of education in China has been continuously improved, and the education level of the labor force has also been continuously improved. The educational hierarchy of human capital has undergone great changes. Some scholars have studied the role of human capital with different levels of education in the economy. They believe that in the short-term, human capital at the secondary education level has a strong positive impact on total output, while high-level human capital is in the economy. An important driving force for long-term growth (Song Guanghui, 2003; Yu Shipu, 2015). Of course, because of the huge differences in education between urban and rural areas, some scholars have studied the relationship between education human capital and the economy from different regional perspectives. The results show that the education level is an important factor affecting the income gap between urban and rural areas (Chen Binkai, 2010; Zhan Guohui, 2017) .

From the existing research, it can be shown that the population aging affects the economy through the role of human capital. In the face of the aging of the population, the policy or a series of systems should reduce the negative impact of population aging. The United States, Japan, and South Korea can be used as a reference to sum up experience on the one hand and learn lessons on the other.

\section{COMPARISON BETWEEN CHINA, THE UNITED STATES, JAPAN AND SOUTH KOREA}

(1)China's aging population is in a grim situation

The acceleration of population aging has become an extremely serious social problem, affecting the development of China's society and economy. The reasons for the current situation of China's aging population are more complicated, and there are many factors. For example, in September 1982, family planning was designated as China's basic national policy, and was enshrined in the Constitution in December of the same year. We don't discuss the correctness of the national policy, but the impact of this policy on China's population and development issues cannot be ignored. Family planning has led to an overall decline in the birth rate of China, which has laid the foundation for China's aging population. The continuous improvement of the medical level and the continuous improvement of the social security system have improved the life expectancy of the population. According to the China Statistical Yearbook 2017, China's average life expectancy has increased from 67.77 in 1981 to 76.34 in 2015. The increase in life expectancy will affect people's behavior, including investment in health and investment in education. A series of actions will further affect the aging of the population.

\begin{tabular}{|c|c|c|c|}
\hline index & $\begin{array}{c}\text { Older } \\
\text { care } \\
\text { ratio }\end{array}$ & Birth rate & $\begin{array}{l}\text { The proportion of } \\
\text { the population } \\
\text { aged } 65 \text { and over } \\
\text { to the total } \\
\text { population }\end{array}$ \\
\hline 2000 & 9.92 & 14.03 & 6.96 \\
\hline 2001 & 10.09 & 13.38 & 7.1 \\
\hline 2002 & 10.38 & 12.86 & 7.3 \\
\hline 2003 & 10.65 & 12.41 & 7.5 \\
\hline 2004 & 10.69 & 12.29 & 7.6 \\
\hline 2005 & 10.67 & 12.4 & 7.7 \\
\hline 2006 & 10.96 & 12.09 & 7.9 \\
\hline 2007 & 11.1 & 12.1 & 8.1 \\
\hline 2008 & 11.33 & 12.14 & 8.3 \\
\hline 2009 & 11.6 & 11.95 & 8.5 \\
\hline 2010 & 11.9 & 11.9 & 8.87 \\
\hline 2011 & 12.25 & 11.93 & 9.1 \\
\hline 2012 & 12.66 & 12.1 & 9.4 \\
\hline 2013 & 13.08 & 12.08 & 9.7 \\
\hline 2014 & 13.69 & 12.37 & 10.1 \\
\hline 2015 & 14.33 & 12.07 & 10.47 \\
\hline 2016 & 15 & 12.95 & 10.8 \\
\hline 2017 & 15.9 & 12.43 & 11.4 \\
\hline
\end{tabular}

Source: "China Statistical Yearbook 2017" 
From the above picture, we can see that the old-aged care ratio in China is in an increasing trend. On the one hand, the birth rate of the population has a tendency to decline; on the other hand, the life expectancy of the elderly is getting longer and longer, and the proportion of the population over 65 is getting bigger and bigger. As China's aging is accelerating, we must not only explore the impact of aging on the Chinese economy, but also learn from other countries' experiences in dealing with aging.

(2)South Korea is likely to become one of the countries with the most aging population

South Korea has a relatively high degree of aging but has the fastest aging rate in the world. According to the United Nations, the population of Korea will reach its maximum in 2020 , the number of adults will exceed that of children, and the number of labor will begin to decline. South Korea is getting older. The transformation of the society into an aging society means that South Korea will face greater pressure from the social security and medical systems. In 2013, Korea's aging rate was $12.17 \%$. According to scholars' prediction, the figure will reach $40 \%$ in 2050, and South Korea is likely to become one of the countries with the most aging population. The speed of Korea's entry into an aging society from an aging society is much faster than Japan (24 years) and Germany (77 years). Korean scholars have shown that if South Korea continues to maintain the current fertility rate, the elderly population in South Korea will account for $48.2 \%$ of the total population by 2100 , which means that in 2100 , every 100 working-age people need to raise 109 elderly people, and the social pension burden is very high and weight.

The aging of South Korea's population has obvious characteristics of urban-rural differences. From the perspective of the aging of urban and rural populations, the aging population of Korean urban population is relatively light, and the rural aging population is increasing rapidly, causing great differences between urban and rural areas. In Seoul, South Korea, and the surrounding satellite city of Incheon and major cities such as Busan, due to the high economic level, young people have a large job-seeking employment, and the aging rate is low, while the rural proportion is high, Gangwon-do, Jeonnam-do, Jeju Island, etc. The old-age population stays agglomerated and the aging rate is relatively high (Wang Zhibao, 2015).

(3)The status quo of super aging brings a heavy burden to Japanese society

The current situation of the Japanese population can be summarized as "super old." Japan is a long-lived country.
In 2003, the average life expectancy was 78.36 years for men and 85.33 years for women. The elderly population aged 65 or older accounted for $19.24 \%$, and it is still on an upward trend. Experts predict that the elderly population over the age of 65 will rise to $33.7 \%$ in 2050 . At the same time, the young population under the age of 15 in 2003 accounted for $14.03 \%$ of the total population, indicating another important feature of the Japanese population - "small child". By 2010, the total population of Japan will begin to turn negative growth, and by 2100 will fall to 67.366 million, which is only a little more than half of the 1998 population.

At present, Japan is the world's most prosperous country and the fastest-growing developed country. From 1960 to 1990, Japan's aging population increased by $6.4 \%$. The United States, Britain, Germany, France and the United Kingdom only increased $3.3 \%, 4.0 \%, 3.5 \%$ and $2.4 \%$. Although Japan did not reach the national standard of aging by 1970, the developed countries of the United States and Europe reached this standard before the Second World War and even in the last century. However, the proportion of the population from the age of 65 to the total population was $7 \%$. In terms of the time required to rise to $14 \%$, Japan is faster than any developed country in the US and Europe.

As a super-aging society, Japan is particularly prone to aging. Japan is the country with the longest life expectancy in the world. The middle-aged population is now more than the young population. Since the middle of the 20th century, the number of Japanese laborers has begun to decline. At the same time, Japan's birth rate has dropped to a record low. This means that the proportion of the elderly population will increase further in the long run. The aging has brought huge pension pressure to Japanese society and the labor shortage has brought about a slowdown in economic growth. According to Japanese scholars, Japan's aging rate will exceed $60 \%$ in 2050, and Japan will further maintain the record of the highest degree of aging. The high proportion of the aging population is a major feature of Japan's aging. Among the 65-69 year-old Japanese, 50\% have labor remuneration, and $25 \%$ of the elderly over 70 years old (more than half are self-employed) are paid. At the same time, Japan's aging is also characterized by aging and feminization. Japan's aging and urbanization are developing at the same time. Therefore, unlike South Korea, the problem of population aging in rural Japan and cities is not very different. From the process of Japan's aging 40 years, it can be found that the reduction of the labor force, the decline in the savings rate, and the heavy burden of the 
working-age population are the heavy shackles brought to Japan by aging.

(4) The United States is preparing to enter the aging society more fully

As the largest economy, the United States has entered an aging society in 1944. In 2017, the elderly aged 65 and over in the United States accounted for about $12.5 \%$ of the national population. It is expected to reach $20.7 \%$ in 2050. Among them, the number of people aged 85 and over will reach more than 18 million, nearly six times that of 1995. In terms of life expectancy, according to the United States Census Bureau, the life expectancy of a population born in 1900 was 47 years, and the life expectancy of a population born in 1950 was 68 years, compared with 77 years in 2000 .

At present, the life expectancy of 65-year-olds of men and women is 16 and 19 years respectively, and in the early 20th century, 11 and 12 years respectively, the life expectancy of men and women aged 65 and older increased by about $40 \%$ and $60 \%$ respectively. In terms of medical needs, about $40 \%$ of the elderly in the United States need to spend some time in hospitals or other care facilities, and about $4.5 \%$ of the elderly will spend the rest of their lives there. Moreover, based on current growth rates, the number of Americans living in nursing homes will reach 3 million in 2030, about twice that of 1995 . These all indicate the unprecedented pressure on the country brought about by the aging of the population. However, it is undeniable that the United States has already had adequate preparations and a better system in dealing with the population aging.

\section{DIFFERENT POLICIES IN DIFFERENT COUNTRIES}

The United States, Japan and South Korea are facing the pressure of population aging, and corresponding policies and measures have been introduced to cope with this pressure. For example, in the 1990s, Japan launched the "Angel Project" to improve children's day care services and other child-rearing services to cope with low fertility status, and to start the "Golden Plan" in 1990 to promote health and welfare services. South Korea's fertility control policy continued to decline after it officially abolished the birth control policy in 1996, and there has not been a rebound. The government has expanded maternity leave and parental leave plans, day care services and so on. These incentive policies are not only to prevent the continuous decline of fertility levels, but more importantly, the aging of the population and the transformation of the old-age model have made the society must assume more important pension responsibilities to make up for the reality of weak family pension. For China, the past population policy focused on the intervention of the number of births, and the future development of aging will put forward higher requirements for population policy from quantity control to service support, and should strengthen economic subsidies for family birth and parenting. Improve the parental leave system, expand home care services, and develop wheezing services for family caregivers.

Although China's aging is neither as high as Japan nor as fast as South Korea. However, Japan, South Korea, Germany, etc. have established and improved the longterm care system for the elderly and the social pension service system to cope with the reality of the aging of the younger generation. The social care service in the United States has also been systematic and standardized. Compared with these countries, there is still a clear gap in China's institutional system for building an aging society. In particular, aging will lead to higher rates of disability and dementia. The elderly with disability and dementia have rigid needs for the care of others. In many cases, specialized nursing and care services are needed. China is still dominated by family pensions, but the increasing number of elderly disabled people and the changes in their families have made it difficult for families to take up the burden of care and to meet the professional service needs of disabled elderly people. The timing of the relatively moderate growth of the number of elderly people in this decade. For China, it is opportunity to increase the basic service facilities, improve the medical care and old-age care system, especially the specialized nursing institutions, community care and nursing centers, etc., and strengthen the training and quality supervision of nursing staff, then effectively responds to the challenges posed by the population aging.

\section{CONCLUSION}

China is facing an ageing problem with certain similarities with the United States, Japan, and South Korea. In response to the aging of the population, the United States, Japan, and South Korea have adopted a number of policies, some of which have significant policy effects, and some not as effective. China can selectively learn from these policies, so that it can more effectively respond to the problem of population aging.

\section{REFERENCES}

[1] Arora S., 2001, "Health, human productivity, and long-term economic growth", Journal of Economic History, Vol. 61, 699-749. 
[2] Becker G. S., Chiswick B. R. "Education and the distribution of earnings", American Economic Review, 1966, 56(1): 358-369.

[3] Cai Wei. Understanding the Supply Side Perspective of China's Economic Slowdown, Economics, 2016(04): 1422.

[4] Cepar Z. Troha M. "Impact of population ageing on education level and average monthly salary: the case of Slovenia", Managing Global Transitions International Research Journal, 2015, 13(3): 281-299.

[5] Chen Binkai, Zhang Pengfei, Yang Wei. Government Education Investment, Human Capital Investment and China Urban-Rural Income Gap. Management World,2010(01):36-43.

[6] Chetty, R., \& Finkelstein, A. (2012). Social insurance: Connecting theory to data. Cambridge: National Bureau of Economic Research, Inc.

[7] Choi, K., \& Shin, S. (2015). Population aging, economic growth, and the social transmission of human capital: An analysis with an overlapping generations model. Economic Modelling, 50(2), 138-147.

[8] Fei Xiaotong. The Problem of Old-age Maintenance in the Change of Family Structure--Re-discussion on the Change of Chinese Family Structure. Journal of Peking University(Philosophy and Social Sciences),1983(03):716.

[9] Fleisher, Belton., and Chen, Jian (1997), "The CoastNoncoast Income Gap, Productivity and Regional Economic Policy in China," Journal of Comparative Economics 252: pp.220-236.

[10] Fleisher, Belton., Li Haizheng and Zhao Minqiang (2009), "Human Capital, Economic Growth, and Regional Inequality in China," Journal of Development Economics, forthcoming.

[11] Grossman M. 1972, "On the concept of health capital and the demand for health", Journal of Political Economics,

Vol. 80, 223-255.

[12] Liu Yufei, Wang Wei. A Review of the Research on the Influence of Population Aging on Human Capital Accumulation. Northwest Population, 2016, 37(01): 99$104+111$.

[13] Luo Kai. Healthy Human Capital and Economic Growth: Data Evidence from China by Province. Economic Science, 2006 (04): 83-93.

[14] Mayer , David, 2001, "The Long-term Impact of Health on Economic Growth in Latin America", World Development, Vol. 29, 1025-1033.

[15] Miller C. "Demographics and spending for public education: a test of interest group influence", Economics of Education Review, 1996, 15(2): 175-185.

[16] Poterba J. M. "Demographic structure and the political economy of public education", Journal of Policy Analysis \& Management, 1997, 16(1): 48-66.
[17] Rubinfeld D. L. "Voting in a local school election: a micro analysis" , Review of Economics \& Statistics , 1977 , 59(1): 30-42.

[18] Song Guanghui. The Contribution of Population with Different Education Levels to China's Economic Growth-An Empirical Analysis of the Relationship between Economic Growth and Education in China (19812000).Journal of Finance and Economics,2003(01):75-81 .

[19] Wang Dihai. Healthy Human Capital, Economic Growth and Poverty Trap. Economic Research, 2012, 47(06): 143155.

[20] Wang Zhibao, Sun Tieshan, Zhang Jiefei.Analysis of Regional Classification and Regional Evolution of Population Aging--Taking China, the United States, Japan and South Korea as Examples. Geographical Science, 2015,35(07):822-830.

[21] Wei Zhong. The Impact of Health on Non-agricultural Employment and Its Wage Determination. Economic Research, 2004 (02): 64-74.

[22] Yu Jiyu. Human Capital, Education Level and Regional Economic Growth--An Empirical Study Based on China's Provincial Panel Data from 1997 to 2012. Shanghai Economic Research,2015(12):97-104+114.

[23] Zhan Guohui, Zhang Xinwen. External Effects of Educational Capital on Urban-Rural Income Gap. Finance and Trade Research, 2017, 28(06): 37-46.

[24] Zhang Chewei. Nutrition, Health and Efficiency: Evidence from Poor Rural Areas in China[J]. Economic Research, 2003(01): 3-12+92.

[25] Zhang Jie, Zhang Junsen, and LEE R. "Rising longevity, education, savings, and growth", Journal of Development Economics, 2003, 70(1): 83-101.

[26] Zhong Shuiying, Yu Yuan. An Empirical Analysis of the Influence of Population Aging and Human Capital Structure on Regional Industrial Upgrading.Statistics \& Decision,2017(16):98-102. 